\title{
A Three Dimensional Model of Corporate Image Configuration: Lesson for Managers
}

Onyeaghala Obioma, H. Ph.D

Department of Business Administration, Federal University Wukari, Taraba State, Nigeria

DOI: $10.36348 /$ sjef.2019.v03i11.001

| Received: 01.11.2019 | Accepted: 08.11.2019 | Published: 12.11.2019

*Corresponding author: Onyeaghala Obioma, $\mathrm{H}$

\section{Abstract}

In this study corporate identity, communication and feedback were put into focus as corporate image indicators. The main research objective was to ascertain whether there is relationship between the above indicators and corporate image designing. Two service organizations based in Port Harcourt were purposively selected to form the study area. 40 employees were chosen from each of the two organizations using the systematic random sampling technique, giving a total sample size of 80. 3-point Likert-type scale was used in constructing the measuring instrument. The research questions were addressed using data collected from respondents. Data was presented using frequency distribution table and histogram. Qualitative statistical analysis was employed by means of simple percentages. Result shows that significant relationship exists between the three measured dimensions and corporate image designing. The implication is that corporate identity, corporate communication and feedback are veritable instruments for corporate image configuration. This means that gaps strongly linked to identity, communication and feedback have a significant effect on the image of organizations. It is recommended that managers should create and communicate positive image of their organization to their publics. They should all the same; discern feedback responses from their publics as reinforcement. This way, organizations at all times, will provide unique value proposition, earn the trust, and support of their publics.

Keywords: Corporate image, Configuration, Woe and Win, Management branding, Reputation Capital.

Copyright @ 2019: This is an open-access article distributed under the terms of the Creative Commons Attribution license which permits unrestricted use, distribution, and reproduction in any medium for non-commercial use (NonCommercial, or CC-BY-NC) provided the original author and source are credited.

\section{INTRODUCTION}

Human resource managers have often had challenges arising from how to position positive image of their organization to the publics. Perhaps more important is the fact that some managers especially those of the profit making organizations are preoccupied with the provision of goods and services for customers without sufficient attention to issues bothering on the image of their organization.

Corporate image configuration is increasingly gaining the attention of organization leaders as one of the approaches of projecting positive organizational reputation. The revitalization of interest is for the fact that all organization needs to position their image positively before their publics. In addition, uncertainties in organization environment necessitate redesigning of strategies in line with changes. Thus, organizations in changing and challenging times need to go back to the drawing board to guarantee that necessary and quality management system which ensures procedures and policies that mold culture of quality within an organization is attained at all times. For instance, before, Nigeria's image to the outside world was battered and Nigerians were seen as bad people. To the rescue was the rebranding of Nigeria project anchored by former minister of information and communication, late Professor Dora Akunyili in 2000; to create a positive image for Nigeria. The project was conceived as an internal process to address the pervading negative perception of Nigeria in the comity of nations.

Today, many organizations are actively working towards creating and communicating a positive image to their stakeholders and the entire society. Conforming to the expectations of the broader society is a common outcome of organizations with unique capability. Such an organization promotes passion and positive behavior in their employees and in the long run, good reputation.

Reputation goes a long way in shaping the image of an organization and its performance at large. In support of the above statement, Fombrun [1] noted that well regarded companies generate hidden assets or reputation capital, which gives them a distinct 
advantage. Advancing the importance of reputation, Young [2] asserts that reputation problems grow like weeds in a garden, and that, direct and indirect costs escalate geometrically". The Institute of Corporate Management and Strategy [3] buttresses the above assertion, saying that a company that mismanages or ignores its image is likely to encounter a variety of problems.

Positive image is an important asset and organizations that build and maintain positive image perform activities differently from others because they are better equipped to meet the changing conditions posed by real world. This means that, an image problem if left unaddressed might make a company find many of its costs of doing business rising dramatically, including the costs of product development, sales support, employee wages, shareholder dividends and so forth.

\section{Problem Presentation}

Divergences have been identified between corporate image and organizational actions, and image problem seems to be rising to high heaven in most organization in Nigeria. Today, many organizations are busy formulating new plans to woe and win customers but they have never felt the need to develop strategies to guide and gauge the type of image they portray before their publics or evolve strategies to reflect constant shifts to changes in their landscape.

Issues on building positive organization image has concentrated on social responsibility and stakeholder expectation theory/perspective and other indicators which may produce better results have not received desired scholarly attention in the past.

Observation has shown that many employees of organizations allow their personal values to interfere with their actions, thereby potentially bringing their actions into conflict with organizational shared values and standards. These employees seemingly overlook image issues which would have helped their organizations responded to the uncertainties in their environment.

Matteson and Ivancevich [4] noted that it is the responsibility of human beings to fashion themselvesto implement self - control in pursuit of their own objectives. But group objective is achieved through team spirit and team spirit is said to exist where people work harmoniously with each other. Yet, in some organization, employees complain about each other and about their work; organization identity is lost, communication and feedback mechanisms are inefficient. One can easily experience growing pains radiating on their faces.

Surprisingly, cohesiveness that should exit in teams is lacking, disconnectedness that often affect rapid growth in the organization is common, poor relationships with the public of business and so forth has become the order of the day. Amazingly, employees that were once defined entirely through relationships, now needs something more to keep them together.

You may agree with me that today, some organization are in a hurry to achieve goals, they forget that most goals worth achieving are not accomplished in sprint mode, but in marathon fashion. In some cases, strategies are changed overnight; management teams are hurriedly changed in a bid to rebrand, re-engineer, reorganize or rescue an organization especially when company offerings no longer satisfy customers or the positive perception about the organization suddenly drops and a lot more. It is on the basis of the above vexing issues that this study was designed.

\section{RESEARCH OBJECTIVES}

The pervasiveness of organizational image requires that management recognize its underpinning dimensions and its impact. This paper sets to investigate and ascertain if corporate image is constructed in relation to corporate identity, communication and feedback mechanism.

Specifically, the study sought to explore the relationship between the following:

- Corporate identity and image of an organization

- $\quad$ Communication and public perception of an organization

- Feedback and reputation of an organization?

\section{Research Questions}

To achieve the objective of this study, the following research questions were designed.

- Does relationship exit between corporate identity and image of an organization?

- Is there relationship between communication and public perception of an organization?

- Does relationship exit between feedback and reputation of an organization?

\section{Significance of the Study}

Today, the media are putting on eagle eyes on organizational practices like never before. This may have informed Downey [5] to say that the urge to expose internal business practices is fed by business analysts, who now routinely supplement, if not supplant, economic performance data with evaluations of organizational strategy, management style and organizational processes.

This study will benefit many organizations, their stakeholders, the government and the larger society. This is because good image is an asset to every organization. It is said that a good name given to a woman automatically reflects to the husband, in like manner, an organization with good reputation or 
positive image, will attract good employees and loyal customers, and at the same time, retain them, make profit for owners (shareholders), pay tax to government and as a spillover effect; the lives of the host community and larger society are affected positively.

When an organization loses its positive image, it loses business. High employee turnover, the disappearance of major customers, and difficulty in getting credit facilities, drop in stock value, and poor relationships with the public of business are some of the problems associated with negative organizational image. It is not good therefore for any organization to experience any of these problems.

\section{Conceptual Framework \\ Concept of Corporate Image}

Corporate image or reputation capital is an important concept and a phrase commonly preached in many organizations, yet, it remains difficult to define. Image incorporates or conjures up perceptions of the public about an organization or reputation of the organization before the public. It represents the impression of the overall corporation held by its several audiences or groups that have a stake in the organization; customers, distributors and retailers, financial institutions and analysts, shareholders, government regulatory agencies, social action organizations, employees and the general public [6].

Corporate image can be said to be the public perception of the experience, beliefs, feelings, and knowledge of an organization. It incorporates the image associated with business name, architecture and variety of products, traditions, ideology and the impression on the quality of communications made by any employee who interacts with the client of an organization.

The Institute of Corporate Management and Strategy [3], describes corporate image as the manner in which a company, its activities, and its products or services are perceived by outsiders. Conceptually, corporate image is a relational construct defined by contrast between 'how an organization is' and 'how others perceive the organization'.

Kotler [7] views corporate image as the consumer response to the overall offering provided by the company and it is defined as the number of beliefs, ideas, and the impression of people (public) in an organization.

Corporate image cannot concoct itself but rather it is shaped by society through communication and openness in the company's efforts to build a positive image. It suffices to say that the image of an organization in the eyes of its stakeholders and larger society is important to the organization. This is because stakeholders are affected by the actions of the company and, in return, their actions affect the company.
The image that stakeholders have of a company will influence their willingness to either provide or withhold support. In this case, the stake holder's theory applies: consumers are principally interested in the price, quality, and reliability of the company's products and services. Financial institutions are concerned with financial structure and performance. The employees are mainly concerned with wages, working conditions, and personnel policies. Government regulatory agencies are required by law to monitor and regulate firms for specific, publicly defined purposes.

If customers develop a negative perception of a company or its products, its sales and profits assuredly will decline. Where government regulatory agencies have a positive perception of the firm, they are likely to be much less censorious. To maintain good image, logically, an organization should tailor its activity to each stakeholder group individually to address the special concerns of that group [8].

Corporate image which is likened to branding in marketing according to Strong and Bolt [9] enhances a sense of identity, creates customer loyalty for a company or product.

\section{Corporate Image Dimensions}

In the process of managing corporate image, the fundamental variables according to http://www.referenceforbusiness.com/small/Co-

Di/Corporate-Image.html\#ixzz3DeuGIxxT are [10]: corporate identity, corporate communication, and feedback. The three dimensions strategy is presented below:

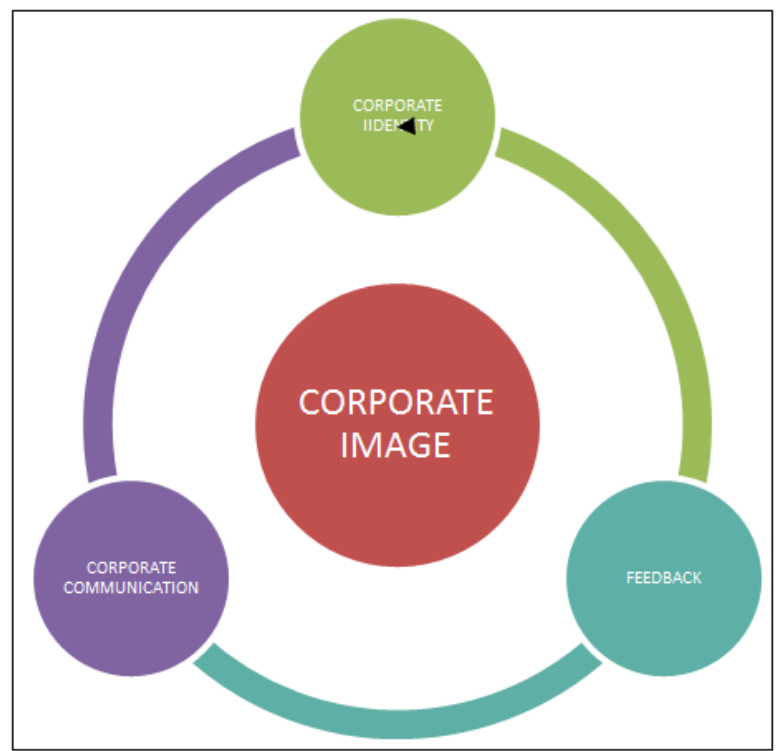

Fig-1: The three Dimensional Model of Corporate Image: Corporate identity, Corporate communication, and Feedback Author's Conceptualization, 2017 
Figure-1 above, shows that corporate identity, corporate communication and feedback are designed around corporate image.

\section{Corporate Identity}

Corporate or organizational identity is the reality and uniqueness of the organization. It refers broadly to what members perceive, feel and think about their organizations. It is an assumed collective, commonly-shared understanding of the organization's distinctive values and characteristics. Corporate identity as a concept build on an idea of what the organization is. It is grounded in local meanings and organizational symbols and thus embedded in organizational culture. Corporate identity is what people perceive about the offerings of an organization; a view supported by Strong and Bolt [9]. The symbolic construction of corporate identity is communicated to organizational members by top management, but is interpreted and enacted by organizational members based on the cultural patterns of the organization, work experiences and social influence from external relations with the environment. It emerges from the ongoing interactions between organizational members (including middlelevel managers) as well as from top management influence.

Employees create identity for the organization which may be accessible through publicity materials, i.e., one can picture the culture of an organization as expressed in the artifacts of that organisation, e.g. a specific colour scheme, dress code or uniforms worn by staff, furniture, design and layout of facilities and so forth. Accordingly, organizations are expected to build good personalities or identities before their publics to earn good image. Identity depicts reputation and good reputation, says Fombrun [1], create wealth, by developing strong and consistent images. For example, a good shopping experience in a supermarket and a right product creates a positive image of the supermarket.

Dutton and Dukerich [11] assert that the opinions and reactions of others affect identity through mirroring and further suggested that mirroring operates to motivate organizational members to get involved in issues that have the power to reduce public opinion of their organization. They reported that the notion of identity is not just about reflection in the mirroring process, it is also about self-examination. Along similar lines, Gioia, Schultz and Corley [12] suggested that image in its multiple guises provides a catalyst for members' reflexive examination of their organizational self-definition. Image often acts as a destabilizing force on identity, frequently requiring members to revisit and reconstruct their organizational sense of self.

Dutton and Dukerich [11] assert that, because organizational culture reflects the values, beliefs and behavioral norms that are used by employees in an organization to give meaning to the situations that they encounter, it can influence the attitudes and behavior of the staff.

\section{Corporate Communication}

Turen [13] says that communicating and promoting the organizational ethos to employees, their acknowledgement and acceptance of it can influence their work behavior and attitudes. Maxwell [14] adds that communication; a form of shared values can help a team to become more connected and more effective. This is because companies communicate identities in many different ways. Communication include almost anything the company does, from the way telephones are answered, clients received and attended to in the work place, to the involvement of company employees in community affairs.

Some of the principal sources of corporate communication include company and product names and logos, formal statements (mission statements, credos, codes of ethics, annual reports, advertising copy, and company slogans), and behavior during important events.

Corporate communication provides the link between corporate identity and corporate image. This is because the objective in managing corporate image is to communicate the company's identity to those audiences or constituencies that are important to the firm, in such a way that they develop and maintain a favorable view of the company. This process involves fashioning a positive identity, communicating this identity to significant audiences, and obtaining feedback from the audiences to be sure that the message is interpreted positively.

\section{Feedback}

Feedback is essential to the management of corporate image. Business owners and managers need accurate information feedback on how they and their company are perceived if they are to make sound decisions. Ideally, feedback should be continuous. As a practical matter, continuous feedback can be elicited from salespeople, clients, employees, and others employees who come in contact with the public of business. Based on such feedback, an unsatisfactory image can be improved by modifying corporate communication, re-shaping the corporate identity, or both. In addition to systematically utilizing internal sources, it is prudent to undertake a serious review of the business's reputation (both internally and externally) on a regular basis.

Dutton and Dukerich [11] buttressed this saying that one might better understand" how organizations behave by asking where individuals look, what they see, and whether or not they like the reflection in the mirror. Defining the mirroring process 
in terms of the link between identity and image, they stated that:

... what people see as their organization's distinctive attributes (its identity) and what they believe others see as distinctive about the organization (its image) constrain, mold, and fuel interpretations... Because image and identity are constructs that organization members hold in their minds, they actively screen and interpret issues...

The implication according to Fombrun [1], Rindova [15], is that the mirror that organizations look into is a metaphorical one. When you look in an actual mirror what comes back to you is a reflection of your appearance. When an organization looks in the metaphorical mirror, it sees its appearance refracted through the eyes of (images held by) others. What others say about an organization is based in their images; refractions of its image through the opinions and judgments of others. This means that organizational identity is at least partially socially constructed through interactions between organizational members and those who give them feedback about the organization.

\section{Theoretical Framework}

This study is rooted on the image theory - four dimensions of living activity otherwise called PAEI Model/Structure.

Image theory image theoryImage theory as propoundedBottom of Form by Lee Roy Beech [16] attempts to construct a broad and inclusive model of decision making as it is really experienced. Image theory holds that an agent's decision making knowledge is taken to be covered by three different images or cognitive schemata: an image of how things should go, an agenda of goals and outcomes they want within specific time windows, and concrete ways or plans for accomplishing those goals and attaining those outcomes. This makes a three-tier hierarchy with principles or values at the top, goals and timelines in the middle and plans at the bottom.

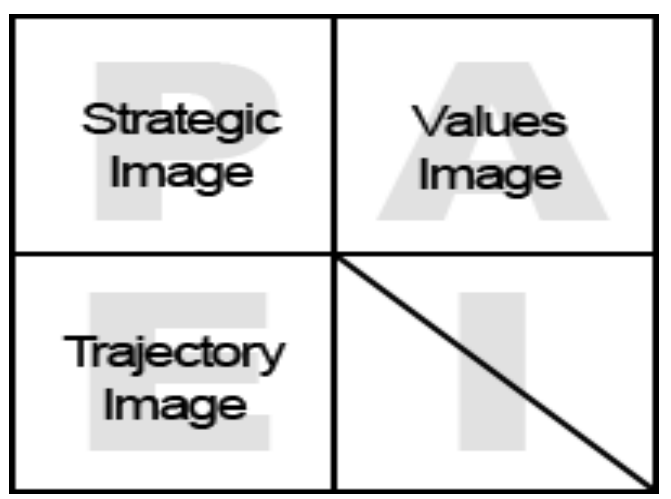

Fig-1: PAEI - Model/Structure

Source: Beach, Lee Roy [16] Image Theory and Decision Making in: http://paei.wikidot.com/beach-lee-roy-image-theory-anddecision-making
In PAE order presented above, the images are:

$P$ - The Strategic Image is plans and tactics for pursuing adopted goals to successful outcomes. It involves anticipation and short-term forecasting.

A - The Value Image: This entails standards, ideals, beliefs, morals, ethics and other principles which serve as imperatives or rigid guides that establish decisions as right or wrong. Principles generate goals and also govern the adoption or rejection of candidate goals and plans or tactics that violate the value image.

E - The Trajectory Image: This is an image of direction or directedness, created by establishing both specific goals and abstract goals, as well as by defining markers of progress towards goals. Timely progression towards desired outcomes is itself a goal within the trajectory image.

EMPIRICAL REVIEW OF LITERATURE

In a study conducted by Ginzel, Kramer and Sutton [17], findings show that an organization's image represents a collaborative social construction between an organization's top management and the multiple actors who comprise the organizational audiences.

Dutton and Dukerich [11] conducted another study on the Port Authority of New York and New Jersey, result indicates that the port authority's organizational identity was reflected in a mirror held up by the opinions and views of the media, community members and other external stakeholders. Dutton and Dukerich [11] further reported that the opinions and reactions of others affect identity through mirroring and suggested that mirroring operates to motivate organizational members to get involved in issues that have the power to reduce public opinion of their organization.

The discrepancy analysis they presented suggest that, if organizational members see themselves more or less positively than they believe that others see them, they will be motivated by the discrepancy to change either their image or their identity.

In a similar study by Albert [18]; Scott and Lane [19]; Hogg and Terry [20] on the theories of individual identification with organizations, result shows that there is relationship between self and organization in terms of individuals' self-definitions and self-reflections.

Ginzel, Kramer and Sutton [17], who were involved in the study of the ways organizational audiences shape organizational impression management efforts, found that impression management is "an interactive process involving organizational actors (top management) and the targets of their influence attempts (the members of the organizational audience)". 
Kotter, ibid, carried out a study he called "The Heart of Change". His survey covered 400 people across 130 companies in 4 continents. Result showed that the secret to change within a company is not about fancy strategy but it is about changing the behavior of the individuals that work there.

Rindova and Fombrun [21] undertook a study on organizational identity. Their finding show that identity is projected to others by broadcasting corporate advertising, engaging in public relations practices, creating and using logos, building corporate facilities, or dressing in the corporate style. This means that there is relationship between these projected images with organizational identity because projected images reflect not only a firm's strategic objectives but also its underlying identity.

Hatch and Schultz [22], conducted a study on the relationship between organizational culture, identity and image. Their position is that contemporary organizations need to define their corporate identity as a bridge between the external position of the organization in its marketplace and other relevant environments, and internal meanings formed within the organizational culture.

\section{METHODOLOGY}

Two service organizations based in Port Harcourt, Nigeria were purposively selected to form the study area. Each of the two organizations had staff strength of not less than 280 employees in their pay roll. 40 employees were selected from each of the two organizations using the systematic random sampling technique, giving a total sample size of 80. Employees chosen were literate and can complete a questionnaire. The questionnaires were distributed and appeal was made to the respondents to candidly fill in their responses based on the scope of the research instrument.

The selected group of employees participated in this structured interview using the questionnaire to describe the current situation in their respective organizations. Three (3) dimensions were extracted to measure against variables from organizational image and were called: corporate identity and image of an organization, communication and public perception of an organization, feedback and reputation of an organization. These formed the principal components of the analysis.

Given the latent character of the variables considered in the study, we used 3-point Likert-type scale: Strongly Agree (SA), Strongly Disagree (SD) and Undecided (UD). The research questions were addressed using data collected from respondents. Qualitative statistical analysis was employed and data was presented using frequency distribution table and histogram. Analysis was carried out using simple percentages.

\section{Data Presentation and Analysis}

\section{Table-1: Measurement of the dimensions}

(1) Does relationship exist between corporate identity and image of an organization?

(2) Is there relationship between communication and public perception of an organization?

(3) Does relationship exist between feedback and reputation of an organization?

\begin{tabular}{|l|l|l|l|l|}
\hline Measured Dimension & SA (\%) & SD (\%) & UD \% & Total (\%) \\
\hline 1) Does relationship exist between corporate identity and image of an organization? & $76(95)$ & $3(3.75)$ & $1(1.25)$ & $80(100)$ \\
\hline 2) Is there relationship between communication and public perception of an organization? & $78(97.5)$ & $2(2.5)$ & $0(00)$ & $80(100)$ \\
\hline 3) Does relationship exist between feedback and reputation of an organization? & $66(82.5)$ & $12(15)$ & $2(2.5)$ & $80(100)$ \\
\hline
\end{tabular}
Source: Survey Data, 2017

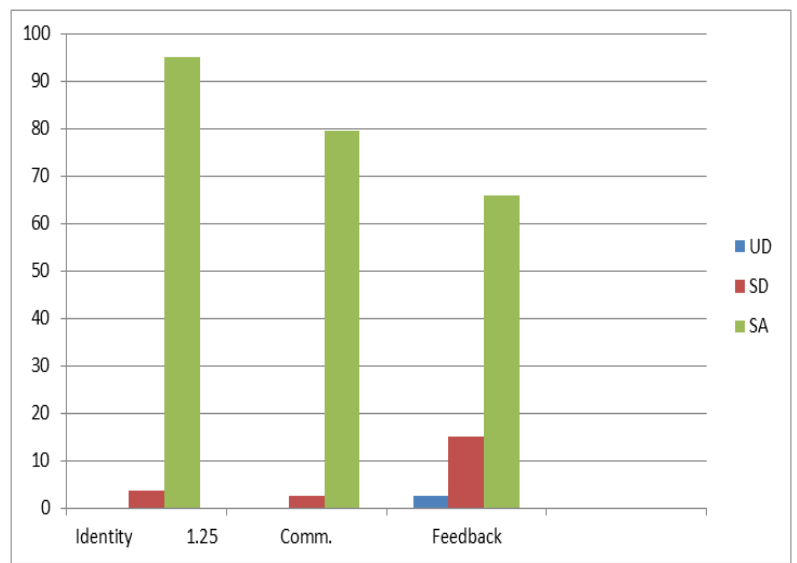

Fig-2: Relationship between corporate identity and image of an organization, communication and public perception of an organization, feedback and reputation of an organization were measured in percentages
Key:

Source: Author's Conceptualization, 2017

$$
\begin{aligned}
& \mathrm{SA}=\text { Strongly Agree } \\
& \mathrm{SD}=\text { Strongly Disagree } \\
& \mathrm{UD}=\text { Undecided }
\end{aligned}
$$

\section{Findings}

Results from data presentation (Table-1 and Figure-2) were used to conduct our analysis. On the relationship existing between corporate identity and image of an organization, 76 respondents representing 95\% strongly agreed, 3 representing $3.755 \%$ strongly disagreed and 1 representing $1.25 \%$ was undecided. It shows that there is significant relationship existing between corporate identity and image of an organization. This finding is supported by Gioia, Schultz and Corley [12], Dutton and Dukerich [11], 
Ginzel, Kramer and Sutton [17], Hatch and Schultz [22].

On the relationship between communication and public perception of an organization: 78 respondents representing $97.5 \%$ strongly agreed and 2 representing 2.55 strongly disagreed. Following this outcome, it shows that there is significant relationship between communication and public perception of an organization. This outcome concurs with the findings of Turen [13].

For the relationship between feedback and reputation of an organization, 66 respondents representing $82.5 \%$ strongly agreed, 12 representing $15 \%$ strongly disagreed and 2 representing $2.5 \%$ was undecided. This means that there is significant relationship between feedback and reputation of an organization. This result is in consonance with findings by Fombrun [1] and Young [2].

Consistent with the results of our research is the outcome of research on corporate image by the Institute of Corporate Management and Strategy [3] whose findings indicates that a company that mismanages or ignores its image is likely to encounter a variety of problems including: drastic rise in costs of doing business, costs of product development, sales support, employee wages, shareholder dividends and so forth.

\section{CONCLUSION AND RECOMMENDATIONS}

Based on the findings above, conclusion is drawn that significant relationship exists between the three measured dimensions and corporate image designing. This means that corporate identity, corporate communication and feedback are veritable instruments for corporate image configuration. This is to say; gaps that are strongly linked to identity, communication and feedback have a significant effect on the image of organizations.

It means that identity, communication and feedback have much to do with organizational image. Thus, we can say that positive organization image raises employee morale, brings about higher employee continuity, and leads to better customer relationships that contribute to greater customer loyalty, lower marketing costs, and enhanced sales. Since the majority of consumers base their purchase decisions partly on trust, if customers perceive negative organizational image, current and future sales levels are likely to suffer, as well, income generation will be affected and the organization may not have the required capacity to conduct its activities. This may culminate to staff layoff and closure of business. To crown it all, a good impression of organizations before their publics fosters positive organizational image.

It is recommended that it is vital that human resource managers and leaders in businesses of all sizes to recognize the importance of creating and maintaining a strong image of their organization, and also make employees aware of it. They should develop good company policies (rather than controlling the damage caused by bad company policies). This will enable them create and communicate positive image of their organization to their publics. As well, they should discern feedback responses from their publics as reinforcement. This way, organizations will at all times provide unique value proposition, earn the trust, and support of their publics.

\section{REFERENCES}

1. Fombrun, C. (1996). Reputation: Realizing Value from the Corporate Image. Harvard Business School Press, Boston. MA.

2. Young, D. (1996). Building Your Company's Good Name.

3. Aligning Core Values, Strategic Vision, Corporate Culture and Image. (2012) in: http://www.studymode.com/essays/CorporateBrand-Management-Aligning-Core-Values1118455.html

4. Matteson, M. T., \& Ivancevich, J. M. (1996). Management and Organizational Behaviour Classics, $6^{\text {th }}$ Edition, USA, McGraw-Hill Companies Inc.

5. Downey, S. M. (1986). The Relationship between Corporate Culture and Corporate Identity, Public Relations Quarterly Academic Journal, Winter 86/87, 31(4), 7.

6. Business? http://managementhelp.org/businessethics?).

7. Kotler. (2011). in: http://reachshools5.blogspot.com.ng/2011/11/corp orate-image-theory.html,

8. Downey 1986 in: http://www.emeraldinsight.com/doi/abs/10.1108/e b060636

9. Strong J., \& Bolt E., (2016). A Qualitative Inquiry into Customers' Perspectives on Branding and the Role of Digital Technologies in $\mathrm{B}_{2} \mathrm{~B}$ : A Case Study of Panasonic, Journal of Customer Behaviour, Academy of Marketing, 15(1).

10. http://www.referenceforbusiness.com/small/CoDi/Corporate-Image.html\#ixzz3DeuGIxxT

11. Dutton, J., \& Dukerich, J. (1991). Keeping an Eye on the Mirror: Image and identity in organizational adaptation. Academy of Management Journal, 34: 517-554.

12. Gioia, D. A., Schultz, M., \& Corley, K. (2000). Organizational Identity, Image and Adaptive Instability; Academy of Management Review, 25: 63- 82.

13. UfukT. (2013). Corporate Brand Management in: http://www.researchgate.net/profile/Ufuk_Turen

14. Maxwell, J. C. (2001). The 17 Indisputable Laws of Teamwork, USA, Thomas Nelson, Inc. Reputation Your Organization Wants and Deserves. 
15. Rindova, V. (1997). The Image Cascade and the Formation of Corporate Reputations. Corporate Reputation Review, 1:188-194.

16. Beach, L. R. (1990). Image Theory: Decision Making in Personal and Organizational Contexts. (Wiley Series in: Industrial and Organizational Psychology. Chi Chester, West Sussex, UK: John Wiley \& Sons.

17. Ginzel, L. E., Kramer, R. M., \& Sutton, R. I. (1993). Organizational Impression Management as a Reciprocal Influence Process: The Neglected role of the Organizational Audience. Research in Organizational Behavior, 15: 227-266.

18. Albert, S. (1998). Identification with Organizations in: Whetten, D., and Godfrey, P. (eds.) Identity in Organizations. Building Theory Through
Conversations. Thousands Oaks. Sage Publications. 209 - 273.

19. Scott, S. G., \& Lane V. R. (2000). A stakeholder Approach to Organizational Identity; Academy of Management Review, 25:43-62.

20. Hogg, M. A., \& Terry, D. (2000). Social Identity and Self-Categorization Processes in Organizational Contexts; Academy of Management Review, 25:121140.

21. Rindova, V., \& Fombrun, C. (1998). In: D. Whetten and P. Godfrey (eds.), Identity in organizations: Developing Theory Through Conversations, 59-66. Thousand Oaks, CA: Sage.

22. Hatch, M. J., \& Schultz M. (1997). "Relations between Organizational Culture, Identity and Image", European Journal of Marketing, 31(5/6), 356-365. 